\author{
ANTON SAID \\ "Hamatmid " Primary School, \\ Ramat-Gan City, Israel
}

\title{
THE SCHOOL EXPERIENCE OF ARAB LGBT STUDENTS IN ISRAEL
}

AвStRact. Said Anton, The School Experience of Arab LGBT Students in Israel [Doświadczenie szkolne uczniów arabskich z grupy LGBT w Izraelu]. Studia Edukacyjne nr 45, 2017, Poznań 2017, pp. 425-433. Adam Mickiewicz University Press. ISSN 1233-6688. DOI: 10.14746/se.2017.45.28

The purpose of the research is to study the school experience of Arab Lesbians, Gays, Bisexuals and Transgender (LGBT) in the state of Israel from own point of view. The research question is: what is the school experience of Arab LGBT graduates of the Israeli educational system in high schools where the language of learning is Arabic?

This is a quantitative research, based on a questionnaire completed by 51 Arab LGBT, graduates of the Israeli educational system. They attended high schools where the language of learning is Arabic; $69.8 \%(\mathrm{~N}=37)$ of them were completed by males, $28.3 \%(\mathrm{~N}=15)$ by females, and $1 \%(\mathrm{~N}=1)$ by transgender. $62.3 \%$ reported that their sexual inclination is homosexual, $22.6 \%$ lesbian, $13.2 \%$ bisexual, and transgender one (1\%). The ages of the respondents range from 18 to 32 . The research participants were recruited through the 'snowball sample' method. The initial request was made to my personal Facebook friends whom I knew were LGBT, and they disseminated the questionnaire to additional LGBT friends they knew.

The questionnaire examined the school experience in general and their perception of the role of the Arab educational counselor particularly on the topic of the sexual orientation and sexual identity, attitudes towards LGBT students, and degree of the influence of traditional Arab society on his role as a school counselor whose role is to advise, help, and accompany all the students so as to integrate in the school and in society in the best possible way. 51 questionnaires were examined in three independent variables of respondents on which the research focuses: the sector to which the respondent's school belongs, the respondent's religion, and the school location.

Key words: sociology, LGBT studies, LGBT in Arab culture, school counselor, Arab Sector in Israel

\section{Introduction}

In the present research study, I will examine the LGBT community in Arab society in the State of Israel, graduates of Arab schools, their school experience, and their perception of the role of the educational counselor in Arab 
society - the degree of influence of conservative and traditional Arab society on the counselor's role and attitudes in general and on the topic of the sexual orientation and identity in particular and the degree of her help and accompaniment of LGBT students, from the respondents' perspective.

In recent years, there is an increase in the percentage of youths who are deliberating the topic of their sexual identity and these chose to reveal their sexual orientation in different environments, including the school ${ }^{1}$. In addition, adolescents with a same-sex orientation 'leave the closet' at younger ages than in the past, when the age of sixteen is the mean age of this action ${ }^{2}$.

Research studies that examined the mental wellbeing of students with a same-sex orientation in the different educational systems in the Western world indicated that the school environment is for the most part a stressful environment for them and they find it difficult to cope with the needs that characterize them. It was found that students with same-sex orientation confirm the argument that the homophobic attitudes conveyed in the school detrimentally influence their sense of self-acceptance and increase the risk of the development of destructive behavior. They do not find a listening ear to their troubles in the formal and informal frameworks in which they spend most of their time. Moreover, it appears that these frameworks are perceived by them as threatening and intolerant of their difference ${ }^{3}$. They express concern about the search for help even from professionals in charge of their wellbeing in the school, including teachers, homeroom teachers, educational counselors, and psychologists ${ }^{4}$. This anxiety is even empowered since there is a high likelihood that these agents will inform their parents about their sexual orientation, contrary to their informed consent.

It is possible to explain the concern of same-sex adolescents about turning to different factors in their school in light of research data according to which

${ }^{1} \mathrm{D}$. Green, Counseling in the process of the formation of the sexual identity during adolescence, [in:] Counseling in the school in a changing society, eds. R. Arharad A. Klingman, Ramot, Tel Aviv 2004, pp. 181-207; A. Pizmony-Levy, E. Kame, S. Lavi, B. Pinchas, M. Menachem, The Israeli educational system from the perspective of homo, lesbian, bisexual, and transgender students: Research report, The Organization of Gay Youth, Tel Aviv 2005 (Hebrew); G. Shiloh, A. Pizmony-Levy, Research on school climate 2008 - The situation of homo and lesbian students in the educational system in Israel. The Organization of Gay Youth, Tel Aviv 2008. (Hebrew)

${ }^{2}$ M. Menachem, B. Pinchasi, A. Pizmony-Levy, Characterization of the needs of youths and young people in the homo/lesbian: community: Research report, The Organization of Gay Youth, Tel Aviv 2003 (Hebrew); A. Pizmony-Levy, E. Kame, S. Lavi, B. Pinchas, M. Menachem, The Israeli educational system from the perspective of homo, lesbian, bisexual, and transgender students: Research report, The Organization of Gay Youth, Tel Aviv 2005. (Hebrew).

3 A. Pizmony-Levy, E. Kame, S. Lavi, B. Pinchas, M. Menachem, The Israeli educational system from the perspective of homo, lesbian, bisexual, and transgender students: Research report, The Organization of Gay Youth, Tel Aviv 2005. (Hebrew)

${ }^{4}$ A. Pizmony-Levy, E. Kame, S. Lavi, B. Pinchas, M. Menachem, The Israeli educational system from the perspective of homo, lesbian, bisexual, and transgender students: Research report, The Organization of Gay Youth, Tel Aviv 2005. (Hebrew) 
teachers tend to respond by ignoring the insults voiced towards homosexuals and lesbians or the acts of violence committed against them ${ }^{5}$. This is although there is a high frequency of harassment and violence against students with same-sex orientation, for instance, the expression 'homo' is intended to be derogatory and shameful and is frequently used to indicate something that is not desired, negative, different, and deviant from the norm ${ }^{6}$. Moreover, students with a same-sex orientation report that often even the teachers themselves make comments that foster a hostile environment that encourages bullying and violence against them ${ }^{7}$.

The present research study is intended to shed light on the school experience of homosexual students and lesbian students, as this is perceived and experienced in their eyes from Western society. It should be noted that few research studies have been performed among homo-lesbian youths in Israel, and regarding Arab society in Israel a research study has not been performed that examined the school experience for LGBT youths in schools that belong to the Arab sector.

Al-Haj ${ }^{8}$ maintains that with all the changes that have occurred in Arab society after the establishment of the State of Israel, the process of moderniza-

${ }^{5}$ J.G. Kosciw, The 2003 National School Climate Survey: The school-related experiences of our nation's lesbian, gay, bisexual, and transgender youth, GLSEN, New York 2004; J.G. Kosciw, E.M. Diaz, E.A. Greytak, 2007 National School Climate Survey: The school-related experiences of our nation's lesbian, gay, bisexual, and transgender youth in our nation's schools, GLSEN, New York 2008; A.H. Grossman, A.P. Haney, P. Edwards, E.J. Alessi, M. Ardon, T.J. Howell, Lesbian, gay, bisexual and transgender youth talk about experiencing and coping with school violence: A qualitative study, "Journal of LGBT Youth", 2009, 6(1), pp. 24-46; A. Pizmony-Levy, E. Kame, S. Lavi, B. Pinchas, M. Menachem, The Israeli educational system from the perspective of homo, lesbian, bisexual, and transgender students: Research report, The Organization of Gay Youth, Tel Aviv 2005. (Hebrew); B. Reis, They don't even know me: Understanding anti-gay harassment and violence in schools, Safe Schools Coalition of Washington State, Seattle, WA 1999.

${ }^{6}$ A.H. Grossman, A.P. Haney, P. Edwards, E.J. Alessi, M. Ardon, T.J. Howell, Lesbian, gay, bisexual and transgender youth talk about experiencing and coping with school violence: A qualitative study, "Journal of LGBT Youth", 2009, 6(1), pp. 24-46; G. Shiloh, A. Pizmony-Levy, Research on school climate 2008 - The situation of homo and lesbian students in the educational system in Israel. The Organization of Gay Youth, Tel Aviv 2008. (Hebrew); J. G. Kosciw, E.M. Diaz, E.A. Greytak, 2007 National School Climate Survey: The school-related experiences of our nation's lesbian, gay, bisexual, and transgender youth in our nation's schools, GLSEN, New York 2008; J. Perotti, K. Westheimer, When the drama club is not enough: Lessons from the safe schools program for gay and lesbian students, Beacon Press, Boston, MA 2001; Pizmony-Levy, E. Kame, S. Lavi, B. Pinchas, M. Menachem, The Israeli educational system from the perspective of homo, lesbian, bisexual, and transgender students: Research report, The Organization of Gay Youth, Tel Aviv 2005. (Hebrew).

7 A.H. Grossman, A.P. Haney, P. Edwards, E.J. Alessi, M. Ardon, T.J. Howell, Lesbian, gay, bisexual and transgender youth talk about experiencing and coping with school violence: A qualitative study, "Journal of LGBT Youth", 2009, 6(1), pp. 24-46; B. Reis, They don't even know me: Understanding anti-gay harassment and violence in schools, Safe Schools Coalition of Washington State, Seattle, WA 1999.

${ }^{8}$ M. Al-Haj, Social research on family lifestyles among Arabs in Israel, "Journal of Comparative Family Studies", 1989, 20, p. 175-195. 
tion in the Arab population is still partial, on the background of the development of asymmetry of the Jewish sector and the Arab sector. In his opinion, there is a great gap between the two sectors in the areas of welfare and health, education and industry.

In Arab society as a collectivist society, the individual belongs to the group, which is supposed to care for him, and in return he is supposed to be loyal to it. The emphasis in this type of society is on the social norms of the group as opposed to the enjoyment of the individual and on the beliefs shared by the members of the group as opposed to the unique beliefs of the individual ${ }^{9}$. One flawed behavior in one member of an Arab family negatively influences the pride, social influence, and marital options of the rest of the members ${ }^{10}$. Hence, the education of children in Arab society emphasizes that conformity to the accepted social image is the most important reason for the change of behavior. The Arab child learns to feel shame as opposed to guilt, since others knew about his negative behavior, and not because of an inner feeling that he has made a mistake and regrets it and judges himself accordingly ${ }^{11}$. Consequently, the Arab child always endeavors to display a positive image and not to reveal the negative aspects of his personality and his life, out of the concern for what others would say about aspects such as his sexual identity, his sexual experience, and so on.

Most people will not be surprised to hear that homosexuality is an extremely taboo subject in the Arab world. In a region heavily influenced by Islam, the idea of homosexuality is seen as antithetical to some of the most important principles of Arab society: family and procreation When people think of homosexuality and the Arab world, the first words that usually come to mind are repression, discrimination, violence, the death penalty, denial, torture, etc. Unfortunately, many of these ideas are true ${ }^{12}$.

Needham ${ }^{13}$ argued that Islam, like Judaism and Christianity, condemns homosexuality and asserts that this is a serious religious sin. Many Israeli Arabs deny the existence of homosexuality in their society. They argue that homosexuality is the outcome of 'Western' influences and the influence of Israeli society, which is 'degenerate', since Israel changed in 1988 the Law

${ }_{9}$ W.B. Gudy Kunst, S. T., Ting-Toomey, E. Chuna, Culture and interpersonal communication, Stage, Newbury, CA 1988.

${ }^{10}$ M. Nydell, Understanding Arabs: A guide for Westerners, Intercultural Press Inc., Yarmouth, ME 1987.

${ }^{11}$ H. Sharabi, A. Mukhtar, Impact of class and culture on social behavior: The feudal-bourgeois family in Arab Society, [in:] Psychological dimensions of Near Eastern studies, eds. L. C. Brown N. Itkowitz, The Darwin Press, Princeton, N.Y. 1977.

12 J. Needham, After the Arab Spring: A new opportunity for LGBT human rights advocacy, "Duke Journal of Gender Law \& Policy", 2013, 20, p. 287-323.

${ }^{13}$ Ibidem. 
against Sodomy and thus, in essence, permitted consensual homosexual sexual relations and is considered one of the more liberal societies in all that pertains to LGBT rights.

As the review of the literature on the school experience for LGBT in the Western world and in Israel shows, the school experience is also not easy, although these are developed and democratic states that support law and liberalism. The situation is far more complicated and difficult in traditional and conservative societies and cultures, like Arab society in the State of Israel.

In light of the aforementioned review, this research study has two objectives. The first objective is to examine the school experience of LGBT and the degree of the influence of their sexual orientation on them in the high school period. The second objective is to examine the perception of the research respondents of the role of the educational counselor in Arab society in Israel and her attitudes on the topic of the identity and the sexual orientation.

The research question is therefore as follows. What is the school experience of Arab LGBT graduates of the Israeli educational system in high schools where the language of learning is Arabic?

I want to examine three independent variables of the respondents who are of interest in the research study: the sector that the respondent's school belongs to (regular Arab school vs. private Christian school), the respondent's religion (Muslim vs. Christian), and the school location (a mixed city of Jews and Arabs vs. an Arab city or village).

The research hypotheses are that the school experience and the perception of the educational counselor and her attitudes towards the topic of the sexual identity are more positive towards the respondents who learned in the private Christian high school, the Christian respondents, and the respondents who learned in the school situated in a mixed city.

\section{Methods}

The research study included 51 participants, all of whom are graduates of the Israeli educational system, in high schools where the language of learning is Arabic. 51 observations were examined in the three independent variables of interest in the research study of the respondents: (1) the sector to which the school belongs, (2) the religion of the student, and (3) the place of the school.

To examine the existence of a relationship between the explanatory variables and the division into the samples, I will use chi-square test. This test will examine the existence of a relationship between the categorical explanatory variables and the division of the sample into groups according to the exami- 
ned variable. The examination of the relationship between the explanatory variables and division into samples will help us examine whether there is a similar dispersion of sub-categories of the explanatory variables in samples, so that we can compare between the groups. If such a relationship is not found, then the samples are similar in their nature in terms of the variables examined and therefore we can compare the indices of the explained variables in the research in every pair of samples. . The explained variables that the research study examines address the following questions:

1. To what extent is the educational counselor in the Arab sector professional and loyal to his role?

2. In your opinion, to what extent is the educational counselor in the Arab sector loyal to Arab society and culture?

3. In your opinion, to what extent is the educational counselor influenced by traditional Arab society and culture?

4. To what extent does the educational counselor in the Arab sector accept homo-lesbian youth more than do the other educational staff members in the school?

5. How much knowledge and awareness does the Arab counselor have on the topic of sexual identity and sexual orientation?

6. In your opinion, to what extent do students from the community receive a solution in comparison to the rest of the students in the school?

7. In your opinion, to what extent does the educational counselor in the Jewish sector accept the orientation of the students in contrast to the educational counselor in the Arab sector?

8. To what extent is your experience in the high school defined as positive?

9. To what extent would you have liked to learn in a more open school than your school?

10. To what extent did your sexual orientation influence your performance as a student from a scholastic perspective?

11. To what extent did your sexual orientation influence your performance as a student from a mental perspective?

12. To what extent did your sexual orientation influence your performance as a student from a social perspective?

\section{Results}

As aforementioned, the examination of the twelve explanatory variables will be performed for every pair of samples in each one of the three variables in which the research is interested. 
Since the responses to the questions were measured on a scale of measurement from an order type of five categories, at the most, we cannot assume that the data in every sample has normal distribution. Therefore, to compare between the samples I will use the Mann-Whitney a-parametric test for independent samples. This test does not assume anything about the distribution of the observations in the groups and examines the difference between the mean of the rankings of the observations between the research respondents according to the sector to which the school where they learned belongs. The null hypothesis in the test is that the classification of the group (Arab/Christian sector) does not have influence on the dependent variables and therefore a random distribution of the responses in the two groups is expected and significant differences will not be found between their rankings.

The test looks at all the questionnaires of both samples together $(\mathrm{N}=51)$ and ranks them from the lowest observation that received the ranking (1) until the highest questionnaire that will receive the ranking (51). If a number of questionnaires with identical value are obtained, then we will calculate for them the mean of the rankings and all will receive this mean ranking. With the end of the ranking, we will return to the original division of the questionnaires according to the different samples, we will summarize the value of the rankings in every group, and we will calculate the mean of the rankings for every sample. Under the null hypothesis of this test, the division into sectors does not influence the respondents' answers, and therefore the mean of the rankings in both groups is expected to be identical.

For the research questions in which a statistically significant difference between the samples is found, we can conclude from the test findings about the direction of the respondents' answers and the meaning of the gap obtained between the means of the rankings of the different samples. In cases where a statistically significant difference is not found between the means of the rankings of the samples, we will conclude that the differences between the mean of the rankings of the group are low. Therefore, we return to examine the values of the means of the responses obtained in the samples so as to examine what we can conclude from the values obtained.

1. The sector to which the school belongs and the location of the school influence:

"the students' perception of the educational counselor in their school as loyal to Arab society and culture". This research study found that the graduates of the private Christian high school and the graduates of the high school located in a mixed city agree more with the question "the students' perception of the educational counselor in their school as influenced by traditional Arab society and culture. The research study found that the graduates of the private Christian high school and the graduates of a high school from a mixed city agree more with the question. 
2. The variable of the school location was found to influence: "the students' perception of the high school as a positive experience". The research study found that the graduates of the high school situated in the mixed city agree more with the question. "the students' perception of the degree of their sexual orientation and its influence on their performance as students from a social perspective. The research study found that the graduates of the high school located in a mixed city agree more with the question.

3. The variable of religion was found to influence: "the students' perception of the degree of their sexual orientation and its influence on their performance as students from a mental perspective". The research study found that the Christian students agree more with the question.

\section{Conclusions}

My research study examined twelve questions that were collected into four parts. Every research question was examined according to three independent variables, so as to examine their influence on their results: the sector to which the school belongs, the religion to which the student belongs, and the place of the school. This research will concentrate together the findings that arose in the examination of the 36 tests I performed in my research study.

This research study found that the graduates of the private Christian high school and the graduates of the high school located in a mixed city agree more that the educational counselor in the Arab sector is loyal to Arab society and culture. The research study found that the graduates of the private Christian high school and the graduates of a high school from a mixed city agree more that the educational counselor in the Arab sector is influenced by traditional Arab society and culture. The research study found that the graduates of the high school situated in the mixed city agree more with the question "to what extent is your experience in the high school defined as positive". The research study found that the Christians agree more that the sexual orientation influences their performance as a student from a mental perspective. The research study found that the graduates of the high school located in a mixed city agree more with the statement that the sexual orientation influences their performance as a student from a social perspective.

\section{BIBLIOGRAPHY}

Al-Haj M., Social research on family lifestyles among Arabs in Israel, Journal of Comparative Family Studies, 1989, 20, pp. 175-195.

Green D., Counseling in the process of the formation of the sexual identity during adolescence, [in:] Counseling in the school in a changing society, eds. R. Arharad, A. Klingman, Ramot, Tel Aviv 2004, pp. 181-207. 
Grossman A.H., Haney A.P., Edwards P., Alessi E.J., Ardon M., Howell T.J., Lesbian, gay, bisexual and transgender youth talk about experiencing and coping with school violence: A qualitative study, "Journal of LGBT Youth", 2009, 6(1), pp. 24-46.

Gudy Kunst W. B., Ting-Toomey S. T., Chuna E., Culture and interpersonal communication., Stage, Newbury, CA 1988.

Kosciw J.G., Diaz E.M., Greytak E.A., 2007 National School Climate Survey: The school-related experiences of our nation's lesbian, gay, bisexual, and transgender youth in our nation's schools, GLSEN, New York 2008.

Kosciw J.G., The 2003 National School Climate Survey: The school-related experiences of our nation's lesbian, gay, bisexual, and transgender youth, GLSEN, New York, 2004.

Menachem M., Pinchasi B., Pizmony-Levy A, Characterization of the needs of youths and young people in the homo/lesbian: community: Research report, The Organization of Gay Youth, Tel Aviv 2003. (Hebrew)

Needham J., After the Arab Spring: A new opportunity for LGBT human rights advocacy, Duke Journal of Gender Law \& Policy, 2013, 20, pp. 287-323.

Nydell M., Understanding Arabs: A guide for Westerners, Intercultural Press Inc., Yarmouth, ME 1987.

Perotti J., Westheimer K., When the drama club is not enough: Lessons from the safe schools program for gay and lesbian students, Beacon Press, Boston, MA 2001.

Pizmony-Levy A., Kame E., Lavi S., Pinchas B., Menachem M., The Israeli educational system from the perspective of homo, lesbian, bisexual, and transgender students: Research report, The Organization of Gay Youth, Tel Aviv 2005. (Hebrew)

Reis B., They don't even know me: Understanding anti-gay harassment and violence in schools, Safe Schools Coalition of Washington State, Seattle, WA 1999.

Sharabi H., Mukhtar A., Impact of class and culture on social behavior: The feudal-bourgeois family in Arab Society, [in:] Psychological dimensions of Near Eastern studies, eds. L.C. Brown, N. Itkowitz, The Darwin Press, Princeton, N.Y. 1977.

Shiloh, G., Pizmony-Levy A., Research on school climate 2008 - The situation of homo and lesbian students in the educational system in Israel. The Organization of Gay Youth, Tel Aviv 2008. (Hebrew) 